\title{
Experiences of domestic abuse within the South Asian community
}

\author{
Mikahil Sulaiman Azad ${ }^{1}$
}

\begin{abstract}
The Black Lives Matter social movement has once again raised important societal issues around structural and racial inequalities. These issues stem from our political and social structures, which are argued to be a continuance of colonial rule and which allow injustice to amplify. There are many who continue to suffer and are often overlooked, namely victims of domestic abuse within the South Asian community. The Domestic Abuse Bill (DAB) is currently going through the Parliamentary process. It is argued that the DAB is flawed due to an absence of provisions and support for minority ethnic groups, namely the South Asian community. Previous scholarly research has documented the prevalence of honour-based abuse within the South Asian community. Despite the unique nature of abuse, this is not acknowledged in the DAB. The purpose of this paper is to uncover the unique experiences of domestic abuse within the South Asian community by thematically analysing two Domestic Homicide Reviews (DHRs). The findings will be discussed using aspects of ultrarealism, namely special liberty, and benign neglect. These findings will form the basis of reasoning behind amendment suggestions for the DAB. Following the thematic analysis of the two DHRs and critical literature review, three recommendations were formed: 1) Removal of 'No Recourse to Public Funds', thus providing funding to all, despite immigration status; 2) Provide education to police officers and GPs regarding domestic abuse and how it often differs depending on culture, namely the South Asian community; and 3) Implement neighbourhood committees across Britain that have a working relationship with the police to identify cases of domestic abuse within this South Asian demographic.
\end{abstract}

Keywords: Domestic abuse, Domestic Abuse Bill, South Asian community, honour, neglect, neo-liberalism, ultra-realism

Domestic abuse is a national, prevalent issue in Britain; it is often to referred to as an epidemic (Frank and Golden, 1992; Hegarty, 2011; Hayes, 2019). This is supported by the latest report from the Office of National Statistics (2020), which notes that in 2019, approximately 2.6 million individuals in England and Wales experienced domestic abuse - 1.6 million women and 786,0oo men. The Office of National Statistics (2020) further adds that there were 671 recorded homicide victims in England and Wales in 2019 - 241 women and 430 men. The report explains that $48 \%$ of female victims were killed in domestic homicide, the majority of which were committed by a male perpetrator whom was a partner of the victim. The COVID19 pandemic caused a national lockdown, which led to further domestic homicides that predominately impacted women (Living Without Abuse, 2020). Oppenheim (2020) and Grierson (2020) note that there is an increase of weekly female domestic homicide victims from two to three. This highlights the nature and scale of domestic abuse in England and Wales. Moreover, it is concerning that national statistics do not record domestic abuse and homicides from honour-based abuse, suggesting the government does not consider it an issue.

Recently, the Black Lives Matter movement has once again revealed the prevalence of structural and racial inequalities. In a post-colonial world, security is heavily influenced by 
Vol. 8, No. 1, 50-68.

economics, policies, and social structures that reflect those of the colonial era. This paper argues that domestic abuse victims within the South Asian community are amongst those who continue to suffer from the effects and are often overlooked. The Domestic Abuse Bill (DAB) is currently going through the Parliamentary procedure. In England and Wales at present, an individual cannot be criminally charged for 'domestic abuse' due to a lack of legislative rigour. Instead, a perpetrator may be charged in relation to individual behaviours that form part of their abusive conduct; for example, actual bodily harm, grievous bodily harm, stalking, or harassment (Home Office, 2016). As such, this makes it difficult to identify cases of domestic abuse from police-recorded crime statistics and omits other behaviours not considered criminal (Home Office, 2016). This is not satisfactory as this system does not account for other acts of domestic abuse. The DAB will establish a statutory definition, which acknowledges emotional, controlling, and economic abuse (Gov.UK, 2020). Furthermore, this Bill will ensure that local councils provide support to victims by providing accommodation and funding (Gov.UK, 2020). Despite the revolutionary nature of this Bill, it can be argued that it does not go far enough. There is a distinct absence of provisions, support, and strategies taking account of the specific needs of minority ethnic groups, notable among them, the South Asian community. Although domestic abuse occurs amongst all communities (Whitehead et al, 2013), research has shown there are acts of abuse that are prevalent in the South Asian community, such as honour killings, forced marriages, and normalisation of patriarchal violence (Gill, 2004; Dyer, 2015; Chowbey, 2017). The unique experiences of domestic abuse within the South Asian demographic is not acknowledged within the Bill. Without provisions set within $\mathrm{DAB}$, this will continue to have a detrimental impact and allow domestic abuse to flourish within this demographic. Research has consistently shown that domestic abuse in the South Asian community is prevalent and many victims are not reporting such abuse due to language barriers, fear of further abuse (from other family members and the community), shame, and because they are unaware of support systems (Gill, 2004; Berman and Chantler, 2005). Despite the nature and impact honour-based abuse has on victims, there remains a reluctance from the social structures to acknowledge and apply policy that can benefit this community. This highlights the continuance of oppression and injustice

This paper is a qualitative investigation that will uncover the unique experiences of domestic abuse within the South Asian community by thematically analysing two Domestic Homicide Reviews (DHRs). DHRs are valuable, in-depth, multi-agency reviews, which focus on the death of an individual that stems from violence, abuse, or neglect (Home Office, 2016). DHRs have been overlooked in academia, despite the insight they provide; this will be further discussed, but it should be noted that in focusing on cases of fatal harm, these reports help examine the full spectrum of abusive behaviour and assist in identifying signs of escalation. Notwithstanding some of the shortfalls of DHRs, which will be outlined later in this paper, the window into the unique experiences of domestic abuse faced in the South Asian community is valuable for research in this area. Following the thematic analysis of the DHRs, this paper will draw upon the results and previous literature to recommend strategies that should be implemented to the DAB. There is a lack of scholarly insight towards the flaws of the DAB, specifically how it does not have any provisions to prevent domestic abuse in the South Asian community. This paper, therefore, will be beneficial for academic insight and society, with the findings forwarded to policy influencers for amendments, thus having a positive societal impact.

\section{Definitions}

\section{Domestic abuse}

The definition chosen is from the DAB. Oncethis Bill has proceeded through the Parliamentary procedure, this will be the standardised definition. Previous scholars have conceptualised 
their own definition, although a criticism of this is that it is overly simplistic, which does not provide an accurate account of domestic abuse. The chosen definition used within this paper is as follows:

Any incident or pattern of incidents of controlling, coercive, threatening behaviour, violence or abuse between those aged 16 or over who are, or have been, intimate partners or family members regardless of gender or sexual orientation. The abuse can encompass but is not limited to psychological; physical; sexual; economic; emotional.

(Home Affairs Committee, 2018: 8) This definition acknowledges forms of domestic abuse other than the physical element, including psychological, sexual, economic, and emotional. Stark (2009) notes the violence model dominated how we previously perceived domestic abuse. It was argued that physical abuse was considered 'real' abuse, which stems from visible injuries. However, in recent years, attention has been re-directed towards 'control' as the epicentre of domestic abuse. Under Section 76 of the Serious Crime Act (2015), controlling and coercive behaviour in an intimate or family relationship was criminalised. Under this legislation, it is an offence for an individual to engage in behaviour that is coercive or controlling to someone they have a personal connection with.

\section{Neo-liberalism}

With regards to the broader context within which abuse occurs, it is important to acknowledge the political economic backdrop to these harms. As such, this paper will refer throughout to contemporary neo-liberalism, which is defined as follows,

The defining features of neoliberalism include economic liberalisation policies such as privatisation, austerity, deregulation, free trade, and reductions in government spending in order to increase the role of the private sector in the economy and society.

(Lynes et al, 2020: 3)

\section{South Asian community}

The South Asian community includes individuals who were born and raised in the United Kingdom, whose families originate from South Asian countries, including Bangladesh, Pakistan, India, and Iraq (Aplin, 2019). It also includes individuals who were born in South Asian countries who have immigrated to the United Kingdom (Gill, 2013).

Scholarly literature surrounding domestic abuse, specifically within the South Asian community, can be divided into four subsections: the feminist movement; concept of honour; interaction with the criminal justice system; and impact of existing policy. It is essential to draw upon the feminist movement, which called attention towards the realities faced by women due to the structures of patriarchy. The second section will draw upon the concept of honour, which led to the normalisation of such acts, including forced marriages and honour killings. Then we will discuss the interactions of South Asian survivors of domestic abuse with the criminal justice system. And finally, we will draw upon the scholarly insights towards British policy, which has a detrimental impact to the South Asian community who are affected by domestic abuse.

\section{The feminist movement}

Feminism is the political and social movement that advocates for gender justice (Naffine, 1997; Nicholson, 2013). The movement argues that society is inherently patriarchal, and women are at a disadvantage from the outset (Whitehead et al, 2013; Bradshaw, 2013). Brooks (2002) notes there are different branches, such as radical, liberal, and black feminism. 
Vol. 8, No. 1, 50-68.

However, all these branches are united with the belief that gender is the social division that has the most significant impact on people's life experiences and opportunities (Black, 2019). The second wave of the feminist movement took place in the 1960s, which included efforts from scholars and activists. This involved drawing attention to the lived experiences of women, which stems from the structures of patriarchy (Dobash and Dobash, 1992; Silvestri and Crowther-Dowey, 2016; Finley, 2016). Heidensohn's (1968) publication, entitled 'The Deviance of Women: A Critique and an Enquiry', critically argued that there is an absence of empirical research focusing on women, including experiences of female offending and injustices. The majority of academic enquiry focuses upon the experiences of men, specifically towards offending (Heidensohn, 1968); albeit without consideration of gendered issues (Ellis, 2017). Heidensohn (1968) adds that when women were discussed in academic publications it was based upon assumptions and stereotypes (Rafter and Gibson, 2004), which stems from the study by Lombroso and Ferrero (1895) entitled, The Female Offender. Lombroso and Ferrero (1895) claimed women who criminally offend are biologically different, known as biological determinism. D'Cruze and Jackson (2009) note that this has impacted criminological research into understanding women as victims and offenders, as focus was still towards biological determinism. Heidensohn's (1968) call to action inspired empirical research to be conducted by women, focusing on the encounters of females as the perpetrators of crime, as victims of crime, and also the interactions of females within the criminal justice system (Silvestri and Crowther-Dowey, 2016). The body of work that followed moved away from biological determinism, instead focusing upon women's experiences as inherentlygendered, which is situated within the structures of patriarchy (Carrington and Death, 2014; Hill, 2019). From the late 1960s and early 1970s, the movement began to address issues that impacted women due to the domination and power of men (Pringle; 1995; Wykes and Welsh, 2008). From the women's liberation, this conceptualised the development of feminist analysis around gendered violence, which focused on men's power and domination of women, which contextualised domestic and sexual violence (Dobash and Dobash, 1992; Wykes and Welsh, 2008). As such, the second wave of the feminist movement advocated for change through grassroots activism and the academy in drawing attention to women's victimization as a legitimate topic for scholarly enquiry (Fraser, 2013). Hall and Winlow (2015) add that the emergence of neo-liberalism from the 1970s detrimentally impacted the criminal justice system in regard to accessing funding for outreach programmes, while Fraser (2013) notes the feminist movement has been absorbed by the neoliberal economy. The neo-liberal economy involves the state reducing costs for public spending, which includes refuge centres for individuals facing domestic abuse (Wykes and Welsh, 2008; Lynes et al, 2020). Domestic abuse was not considered an issue for the government, despite the prevalence and impact, and so gaining funding for refuge centres is problematic (Fraser, 2013). Furthermore, the neo-liberal emphasis upon personal responsibility and the meritocracy assumes a level playing field within which the onus is placed upon the victim to 'just leave', and women are often blamed for their own victimisation (Yardley, 2020). Domestic abuse is understood as their personal failure to take responsibility for their own safety, and this emphasis upon the female victim rather than the male perpetrator's decision and choices to do harm is, some argue, evidence of neo-liberal patriarchy (Yardley, 2020). A criticism towards the feminist movement is the lack of complexity (Rottenberg, 2013; Hall and Winlow, 2015). The feminist movement is centred towards the social division of gender; there is lack of attention paid to differences between women (Whitehead et al., 2013). This has gathered 'all women' together, assuming there is a consensus of experiences (Yardley, 2020). It is argued the feminist enquiry does not go far enough in explaining the root causes, which allows patriarchy to continuously amplify (Yardley, 2020). Although there has been significant progress in academia regarding domestic abuse, there continues to be a lack of enquiry into this issue within the South Asian community. 


\section{Concept of 'honour'}

Many have theorised 'honour' to be the catalyst for domestic abuse within the South Asian community (Gill, 2006; Gill, 2013; Aplin, 2019). The concept of 'honour' is the sense of pride attached to a family when long-lasting traditions, customs, and behaviours are upheld (Gill, 2017). The nature and scale of honour-based abuse in Britain is dubious, although research indicates prevalence in the South Asian community, it is not nationally recorded (Begikhani et al, 2016). Referring to Aplin (2019), honour-based abuse is physical, psychological, and coercive actions with the intention to maintain the family 'honour'. Although honour-based abuse occurs amongst many cultures, it is prevalent within the South Asian community (Roberts et al, 2013). Referring to Gill (2004), a family's honour is highly dependent of the actions and behaviour of women, specifically mothers and daughters (Yuval-Davis, 1998; Shahid and Hyder, 2008). When female members of the family do not comply with actions that emphasise family honour, it is said to bring 'shame' on the household (Brandon and Hafez, 2008; Begikhani et al, 2016). The control of women is a key symbol of male pride within an honour-centric society (Gill, 2013; Gill et al, 2012). Stark (2009) notes that coercive control is the backbone of domestic abuse. For domestic abuse to happen there needs to be control over another person (Stark, 2009). In application to the concept of 'honour', it is often considered that women are inferior and, therefore, that control has been established in accordance with cultural norms (Stark, 2009; Gill, 2013). 'Shameful' acts involve wearing nontraditional clothing, socialising with individuals from a different culture, and marriage without family approval (Gill, 2017). In an attempt to restore 'honour', physical violence is often carried out from male members of the family as punishment (Wilson, 2009). The narrative of 'honour' is the backdrop for individual experiences of abuse; domestic abuse literature and policy response has often failed to acknowledge this important contextual issue (Gill et al, 2012; Aplin, 2018). In some cases, honour-based abuse culminates in domestic homicides, known as 'honour killings' (Dyer, 2015; Aplin, 2018). Honour killings occur when a family agrees a member has violated the 'code of honour' (Aplin, 2019). To 'cleanse' this dishonour, the individual is killed (Dyer, 2015). There are distinct criticisms towards literature surrounding domestic abuse, notably from Johnson (2010) and Brooks-Hay et al (2018), as these sources decided not to discuss honour-based abuse. Instead, it is continuously written in a separate strand of literature, which highlights the marginalisation of the South Asian demographic in academia. Ensure honour is upheld often leads to forced marriages; Aghtaie and Gangoli (2014) argue that the merging of households impacts the family's level of honour, especially if the other family has a 'high status'. Forced marriages often occur when an induvial is taken abroad (Gangoli, 2006; Helie and Hoodfar, 2012; Fulu, 2014). Therefore, it is difficult for the police to intervene, given the cross-jurisdictional challenges this creates, and the nature is unknown due to it taking place in another country (Gangoli and Razak, 2006; Aplin, 2019). Dauvergne and Millbank (2010) acknowledge the failure of international laws, although legal frameworks have been conceptualised to prevent this issue, such as Article 8 of the European Convention of Human Rights (ECHR, 2020). This highlights that forced marriages and honour-based abuse is not considered an issue due to a lack of action from international governance. Although the concept of honour impacts women predominantly, it also has a detrimental impact towards men (Gill, 2016). There is an expectation for men to uphold the family's honour by carrying out acts of masculinity (Gangoli, 2006; Broom et al, 2012). When this is not shown, they are often degraded by senior family members, namely parents (Gill, 2016; Aplin, 2018). It has been consistently argued when discussing domestic abuse within the South Asian community, that the focus should be towards 'race' and 'culture', due to cultural differences (Raj and Silverman, 2002; Niaz, 2003; Gangoli and Razak, 2006). Reddy (2008) argues the South Asian community has been heavily impacted by the neo-liberal economy, as it encourages individuals to maintain self-interest, best others with competitiveness, and 
Vol. 8, No. 1, 50-68.

exercise their autonomous choices (Rottenberg, 2013; Tudor, 2018). Rottenberg (2013) and Fraser (2013) claim domestic abuse embodies the political structure of neo-liberalism in regard to the controlling of others and domination, which is a reflection upon honour-based abuse (Gill, 2013; Gill, 2019).

\section{Interaction with the criminal justice system}

The relationship between the South Asian community is less than cordial with the police, which is exacerbated by frequent stop and search incidents (Aplin, 2019). As a result, this manifests dis-trust between the South Asian community (Aplin, 2018). As such, women from these communities are considerably less likely to call the authorities, so their victimisation goes unreported and unrecorded (Aplin, 2019). When survivors within the South Asian community attempt to report their abuse, there is often a language barrier (Ahmad et al, 2009). This is supported by Carr and Campbell (2018), who explain that since the establishment of the coalition government in 2010, this has severely impacted the criminal justice system due to budgets cuts, specifically towards the translation services. This is imperative for ethnic minority survivors of domestic abuse in reporting to the police and in court. Once translation was achieved, the police were then culturally ignorant towards honour-based abuse (Belur, 2008; Aplin, 2019). When survivors explained their experiences of being in danger from the entire family because she has brought 'shame' to their household, the police did not understand the issue due to not being trained or equipped to provide support (Monckton-Smith et al, 2014; Aplin, 2018; Aplin, 2019). It is noted by Monckton-Smith et al (2014) that there is a hierarchy of victims surrounding domestic abuse. This refers to the level of response given by the police when reacting to domestic abuse. This hierarchy is based upon ethnicity; the South Asian community is significantly low on the scale (Monckton-Smith et al, 2014). Police officers have shown to be unsympathetic towards the South Asian community when addressing honour-based abuse (Philips and Dustin, 2004; Gill, 2012). When a survivor reports to the police their abuse, this is considered 'being against the family' and has brought upon 'shame' (Gill, 2012). The privacy of the family has been embodied from the neo-liberal economy in regard to keeping family matters 'private', and thus maintaining societal status of a happy family (Bumiller, 2008; Fraser, 2013). As a result of the failure of police response, which stems from cultural ignorance, this amplifies domestic abuse within the South Asian community (Gill et al, 2012).

\section{Impact of policy}

Despite the second wave of the feminist movement from the 1960s, there has been a paucity of policy benefiting survivors of domestic abuse (Fraser, 2013). Many survivors of domestic abuse within the South Asian community have immigrated after marrying a British citizen (Ahmad et al, 2009). When an immigrant joins their spouse in Britain, they have a two-year probationary period before becoming a British citizen (Anitha, 2010). If the marriage ends during the probationary period, this will resort in deportation (Thiara and Gill, 2009). This policy forces individuals to remain with their abusive spouse without access to public funds, otherwise they will face deportation - this is known as 'No Recourse to Public Funds' (Anitha, 2010; Sharma and Gill, 2010). Perpetrators use this policy as blackmail against their spouse to maintain silence about their experiences, otherwise they will terminate the marriage (Sharma and Gill, 2010; Mirza, 2016). When survivors reported to agencies regarding their abuse, they refused to provide assistance or support due to their immigration status (Sharma and Gill, 2010; Gill, 2017). Many survivors were advised to return home or 'back to where you came from' from their local council (Mirza, 2016: 598). Due to a lack of policy action and support towards survivors of domestic abuse within the South Asian community, it implies there is 
racism and sexism embedded in the state (Fraser, 2013). This is shown within the Domestic Abuse Bill; despite the unique experiences faced within the South Asian community, which stem from the concept of honour and the impact from pre-existing policy, there is paucity of recognition. Drawing upon the first subsection, when discussing the feminist movement, as a result of focusing specifically upon gender and dismissing ethnicity (Black, 2019), this has led to the conceptualisation of a flawed Bill, which does not acknowledge honour-based abuse. Therefore, there must be an amendment that implements strategies to support the South Asian community.

The feminist enquiry focused on the social division of 'gender' in empirical research due to the structures of patriarchy. Focus was then directed towards domestic abuse within the South Asian community in Britain. Despite the prevalence of domestic abuse within the South Asian community, there remains a lack of research, especially towards the concept of 'honour'. This literature review drew upon domestic abuse within the South Asian community in relation to 'honour' and the criminal justice system. Moreover, domestic abuse survivors within the South Asian community are severely impacted by existing national policies and there is a lack of inclusion in the DAB. There is a lack of academic insight arguing for amendments to benefit this demographic. In addition, it was found that the neo-liberal economy has been embraced by the cemented patriarchal structures, which has bolstered misogynism and crimes that predominantly impact women, namely domestic abuse. This has not been applied in academia towards domestic abuse in the South Asian community. To provide a contribution to knowledge and explore a new dynamic in making sense of this issue, it is essential to utilise a paradigm that acknowledges the neo-liberal economy.

\section{Theoretical framework}

Referring to previous research, a common flaw was the use of outdated criminological theory to make sense of domestic abuse, namely feminism (Heidensohn, 1968; Pringle, 1995; Brook, 2019). Whilst this theoretical framework underpinned important changes in awareness and policy around formal sex equality, whether it is fit for purpose in explaining and tackling domestic abuse in the twenty-first century is debatable (Wykes and Welsh, 20o8; Reddy, 2008). The feminist theoretical framework is flawed in making sense of domestic abuse as it has been absorbed by the neo-liberal economy (Fraser, 2013). The patriarchal structures have embraced neo-liberalism, which has bolstered misogynistic views and beliefs (Yardley, 2020). Due to becoming part of the policy process, it can be argued that the feminist movement has hamstrung its capacity to facilitate the systemic changes needed to tackle violence against women (Wykes and Welsh, 2008). Furthermore, it was evidenced that domestic abuse within the South Asian community can be understood in a neo-liberal economic context (Reddy, 2008; Mirza, 2016). Although domestic abuse within the South Asian community exists outside of a neo-liberal context, in Britain it has been amplified as a result of this cemented political economy (Belur, 2008).

The ultra-realist branch of criminological theory has provided in-depth insights towards inter-personal violence, offenders, and harm in recent years (Winlow and Hall, 2013; Hall and Winlow, 2015; Rahman, 2019; Yardley, 2020). This paradigm argues that criminologists should observe the aetiologies of crime, as well as the external forces that manifest harm, namely consumerism and market competitions (Hall 2012; Rahman, 2019; Yardley, 2020). Due to the wide scale of ultra-realism, only specific aspects of ultra-realism will be utilised, namely special liberty (Hall, 2012) and benign neglect (Treadwell et al, 2020). Neoliberalism, a by-product of capitalism, was established in Britain in the 1970s (Hall and Winlow, 2019). The change of political economy eradicated traditional cultures into the form of consumerism (Leitner et al, 2007; Hall and Winlow, 2015). In doing so, this warranted individuals to undertake special liberty (Tudor, 2018; Yardley, 2020). This concept 
Vol. 8, No. 1, 50-68.

embodies the structures which have been established through consumerism. The neoliberal structure emphasises the importance of status and maintaining self-interest (Tudor, 2018; Rahman, 2019). Therefore, this has been embodied within individuals, which enforces the actions around one's self and pursuit desires for the purpose of self-interest, status, and influence, despite the harms caused to others. This is known as special liberty (Hall, 2012). Benign neglect is a newly added concept to the ultra-realist paradigm by Treadwell et al (2020). This concept is the attitude of ignoring a delicate situation by those who are responsible in the hopes that it will result in the best way possible, consequently creating harm for many (Treadwell et al, 2020). Referring to previous research, it was evidenced that policy in the neo-liberal economy has a crucial role in amplifying domestic abuse (Anitha, 2010). Despite the harm caused to many, it remains ignored by social actors embedded within institutions (Treadwell et al, 2020). To add to knowledge and understand whether incorporating a socio-economic lens can make sense of domestic abuse within this demographic, it is imperative to use this paradigm. In addition, Yardley (2020) expertly demonstrates the use of ultra-realism when discussing domestic abuse in regard to tech-facilitated abuse, thus supporting the use of this paradigm.

\section{Data set}

Criticisms towards primary research was that it placed significant psychological harm towards survivors of domestic abuse, as it brought individuals back to a state of suffering and harm (Gill, 2012; Khan et al., 2018). Moreover, this study was conducted during the COVID-19 pandemic and, therefore, it was not feasible to conduct primary research in the allocated time. Taking these factors into consideration, a secondary, desk-based approach was chosen. DHRs are multi-agency reviews, which focus on the death of an individual that stems from violence, abuse, or neglect by a person who they are related to, used to be related, has been in a personal, intimate relationship, or someone from the same household (Home Office, 2016). A DHR is carried out when a case has been identified that should have been given attention from public services but resulted in the death of the victim of domestic abuse (Home Office, 2016). For a DHR to commence, it involves the Community Safety Partnership (CSP) to establish a review panel for the case. The panel will elect an independent chair who will oversee the review process and produce the report.

The DHRs that will be used are from 2011-2013 and took place in the West Midlands. According to Dyer (2015), it was evidenced that the South Asian community is prominent in the West Midlands, therefore, DHRs were chosen in this specific region. For the purpose of this investigation, the researcher selected DHRs that impacted individuals from the South Asian community. Referring to Rowland (2019), there are notable flaws to DHRs, specifically the level of subjectivity involved from the reviewer. Rowlands (2019) notes that when the reviewer conducts the investigation, there is the potential for the report to be exaggerated when discussing factors that led to the death of the victim; this raises doubts towards the credibility. However, the Home Office (2016) explains the reviewer is accountable to the CSP who reviews the report, thus eliminating bias or exaggeration through scrutiny. This paper defends the use of DHRs, as they provide valuable information when discussing the experiences of the victims' and interviews with secondary victims (Home Office, 2016). This provides significant background knowledge regarding the abusive relationships.

Both DHRs only focused on female victims. It is argued that by using this data set, we will be ignoring male victims. To counter this criticism, when recommending amendments for the $\mathrm{DAB}$, evidence from previous research will be utilised, which incorporates narratives of male survivors of domestic abuse within the South Asian community. Two DHRs were chosen for this investigation in order to achieve the necessary depth of analysis to address the research questions. It is argued fewer cases are required to enable the 
researcher to better investigate issues that the literature has identified. Additionally, if a greater amount of DHRs were examined, this would limit the researcher from engaging with critical analysis.

\section{Data analysis}

Braun and Clarke (2006) and Guest et al (2012) note that thematic analysis is the method of identifying, coding, and reporting themes within a data set. This method of data analysis is used to identity re-occurring themes that are present within the data and understand the underlying meaning of the context (Guest et al, 2012; Bryman, 2016). Referring to Braun and Clarke (2006), a significant factor towards thematic analysis is the theoretical feasibility, which differs to interpretative phenomenological analysis (IPA) (Largan and Morris, 2019). According to Matthew and Ross (2010), methods such as IPA are bounded by the epistemological positions, which is argued to limit the results due to this constraint. Therefore, this research investigation has the freedom to analyse the data without methodological boundaries. The researcher will identify themes that are present in previous literature, such as honour, economic abuse, immigration, and policy. In addition, the researcher will identify other themes that are consistent and prevalent in both DHRs. This paper argues amendments are needed for the DAB; identifying key themes is a necessary first step in getting to grips with an issue and, therefore, thematic analysis is ideal for this research.

\section{Domestic homicide review 1: Maddocks (2017)}

In June 2013, a British, Muslim woman, aged 27, was killed by her husband, aged 37, by strangulation in Birmingham, UK. For the purposes of this paper she will be named Anna. The perpetrator and Anna got married in Bangladesh in 2004. The perpetrator was a British citizen and was able to bring Anna to the UK with a two-year spouse sponsor visa. Anna's uncle highlighted that she reported her abuse to the police many times. When interviewed by the police, however, Anna dismissed her injuries as self-inflicted. When Anna visited her general practitioner (GP), she also told the doctor her injuries were self-inflicted. It was discovered that the perpetrator loaned money to Anna's mother in Bangladesh. This was used as blackmail to prevent Anna from reporting to the police. According to interviews with Anna's relatives, her husband stole approximately £3,000-£4,00o. Anna was unemployed and dependent on her husband. Anna's relatives add that a significant reason as to why the perpetrator stole from Anna was due to the purchase of land in Bangladesh and for property to be transferred to his name. Relatives mentioned in interviews that money, land, and property rights were often causes of arguments, which led to abuse and coercion. In 2013, Anna reported to the police that her life was threatened. From 2008-2013, Anna reported over 20 times to the police regarding her abuse. She also consistently attempted to communicate with her GP about her abuse when trying to end the marriage, but she was consistently ignored. The police failed to react to the issue and Anna was later killed by her husband. The perpetrator pleaded not guilty but was convicted of the murder. He was sentenced to 15 years in prison.

\section{Domestic homicide review 2: Ross (2014)}

In July 2011, an Indian woman, aged 34, was killed by her partner in Sandwell, West Midlands. For the purposes of this paper she will be named Diana. In 2007, Diana arrived in the UK with her husband and daughter. Diana's husband had British citizenship. Diana displayed signs of abuse to her GP, such as malnourishment, scars, and bruises. Diana's husband was 
Vol. 8, No. 1, 50-68.

unemployed and an alcoholic. He often forced Diana to influence her family to send money over to him. It is unknown how much was sent; it was approximately £2,0oo according to Diana's relatives. Diana told the GP about her abuse and that she had been raped by her husband. The GP failed to report this to law enforcement. Diana's family encouraged her to stay in the marriage, to avoid bringing 'shame' to the family. Diana left her husband in 2010 and then became involved with another abusive partner. Diana's new partner continuously abused and raped her. She again decided to leave the relationship, but when her partner found out she was leaving he strangled her. The perpetrator turned himself to the police; he was sentenced to life, a minimum of 15 years.

\section{Findings}

\section{Institutional neglect}

A prevalent theme amongst the DHRs was institutional neglect. This refers to poor practice from institutions that are meant to support and protect people (Sharma and Gill, 2010). This was discovered in relation to the police, general practitioners (GP), and the local council. It was found that these institutions impacted the experiences of domestic abuse for Anna and Diana based upon their South Asian ethnicity.

\section{Police}

According to the DHR by Maddock (2017), the police had many opportunities to investigate and prevent the abuse towards Anna; 'It is the police who are the focus of this review in regard to the information they had on four occasions between May 2008 and June 2013.' As a result of the negligence from the police, abuse continued and escalated, which led to Anna's death. This is further elaborated in the following quote, 'In June 2012 the second contact with the police was recorded when the victim reported that she was being prevented by the perpetrator from leaving the marriage. The police advised the victim to contact the local Citizen's Advice Bureau. The incident is not recorded as domestic abuse and no referral was made to children's social care or to any other service.' Maddock (2017) quotes, 'difficulties in understanding dynamics and power relationships, cultural issues'. This ignorance impacted Anna in terms of her receiving support; instead of supporting Anna, the police referred her to another institution. It is observed that the police were culturally ignorant to honour-based abuse towards Anna and, as a result, they were unaware of how to assist. Instead, the police pushed the responsibility to the Citizens Advice Bureau without consideration to how the abuse will persist. Furthermore, when police officers were called to Anna's house they were very unsympathetic and did not take the situation seriously. The Individual Management review judged that the police officer did not consider this issue a priority: 'The officers specifically said that it was not a "domestic incident". The statement was of poor quality according to the individual management.' This quote suggests that the officers treated Anna differently based on her ethnicity. As a result of this neglect, this led to further abuse and Anna's death. Despite the negligence and severe consequences, the police officers did not receive any reprimand, showing that educating police officers on cultural awareness is not a priority.

In the DHR by Ross (2014), it discussed how Diana felt judged when reporting to the police about her experiences: 'She had previously expressed concerns about the stigma involved in disclosing the details of such an offence.' From this quote, it is observed that within the police there is an environment in which stigma around different cultures is able to flourish. As a result of the cultural ignorance from the police, it is observed that Diana felt neglected, as she felt judged for attempting to disclose details of her abuse; the abuse continued to amplify, leading to her death. 
General practitioner (GP)

In the DHR by Ross (2014), the reviewer discovered that Diana often told her GP about her abuse and that she was being raped by her partner. The GP did not report this to law enforcement: 'But did not take any further action or make referrals to any agencies or enquire.' This shows that the GP neglected the survivor, despite duty of care to all patients. In section two, paragraph two, it says, 'There is nothing to indicate that either GP followed up their advice about contacting the police or made a referral to MARAC or any other services'. This quote suggests the GP was aware of the abuse towards Diana and, instead of collaborating with the police to ensure her safety, the GP decided to ignore it. The GP considered it a cultural issue; this interpretation comes from the quote in appendix one, section two, page 35, 'This constant attitude by the GPS raises the question of whether they were ignorant of the appropriate treatment for victims'. This shows that the GP made the decision to ignore Diana's suffering based upon her South Asian ethnicity. Despite the GPs actions towards Diana, the DHR does not mention whether the medical practitioners faced disciplinary consequences, which suggests that the institution did not value Diana's life.

Local council

According to the DHR reported by Maddock (2017), Anna was financially dependent on her husband. The council refused to provide support for Diana because of her immigration status, which is known as 'No Recourse to Public Funds': 'Was reliant for continuing residency during the first two years on the spouse visa and had little English and no apparent source of independent income'. This was used as blackmail for deportation by the perpetrator: 'Perpetrator had threatened to send the victim home to Bangladesh'. These quotes highlight the fact that the local council refused to support Anna in terms of accommodation or living funds due to her immigration status. As a result of the neglect from the local council, the perpetrator was able to use that as blackmail to maintain abuse. This shows how current policy is being used as a tool by the perpetrator to maintain abuse. Furthermore, this shows how local councils are implicit in the continuation and amplification of abuse. The local council did not refer Anna to any third-party organisations for support, such as Women's Aid or the Citizens Advice Bureau: 'The victim does not seem to have been advised to seek legal advice over and above going to the Citizen's Advice Bureau.' This shows the local council's reluctance to support, suggesting they did not value Anna based upon her ethnicity.

There is an absence of multi-agency cooperation in place to support survivors of domestic abuse, specifically within the South Asian community. It was shown that police officers and GPs dismissed survivors by pushing the responsibility to another agency, which as a result allowed the abuse to amplify.

Both of the victims within the DHRs were failed by government institutions, namely the police, local councils, and GPs. They failed to react, which led to the deaths of Anna and Diana. Prior to the 1960 and the second wave of feminist movement, the established patriarchal structure in Britain enforced misogyny and dismissed issues that predominantly impacted women, namely domestic abuse, and even more so in the South Asian community (Gill, 2006). Since the 196os, activists have fought for recognition regarding honour-based abuse (Gill, 2012; Gill, 2013). It was not considered an issue for Britain, rather a 'cultural problem' (Anitha, 2010; Payton, 2014). Therefore, the South Asian demographic was severely neglected, leading to consequences within other institutions, which will be elaborated further. It is argued that the government wanted to ignore honour-based abuse, hoping it would eventually disappear (Gill, 2012). From the 1970s the neo-liberal economy emerged, which tropes actions such as aggression, possession, and dominance over others, which was accepted by the patriarchal structure as it bolstered misogyny and institutional racism (Bimbi, 2014; Ellis, 2017; Yardley, 2020). This has brought upon severe neglect towards 
Vol. 8, No. 1, 50-68.

victims and survivors of domestic abuse within the South Asian community (Gill, 2012; Treadwell et al, 2020). In regard to national policy, it has specifically targeted and impacted ethnic minorities who suffer domestic abuse, namely the 'No Recourse to Public Funds' (Anitha, 2010; Mirza, 2016). This policy prevents those who are in the UK during the twoyear probationary period from receiving public funds for accommodation and living expenses (Wilson, 2009), allowing domestic abuse to flourish, as otherwise the survivor is forced to deport (Sharma and Gill, 2010). Anitha (2010) mentions that although this policy can impact survivors amongst many cultures, it severely impacts the South Asian community as many survivors have immigrated across South Asia. As a result of the British government's reluctance to understand the dangers and prevalence of domestic abuse within the South Asian community, this has trickled down to the police, in which they remain unaware of cultural differences (Sharma and Gill, 2010; Aplin, 2019). As shown in both DHRs, the police neglected signs of domestic abuse due to cultural ignorance, which stems from governmental failures. The GPs in both DHRs failed to report to authorities or law enforcement, even though it was their responsibility to do so. They neglected their duty of care towards Anna and Diana. It is argued that the GPs embodied the same governmental response, by claiming it was a 'cultural problem', it was not their concern, and the best course of action was to ignore the suffering (Treadwell et al, 2020).

\section{The perpetrator maintaining 'honour'}

Another theme that was prevalent amongst both DHRs was the perpetrator maintaining 'honour'. The two relevant subsections of this are superiority and financial abuse.

\section{Superiority}

In the DHR by Ross (2014), it was found that Diana's husband wanted to remain superior through physical and coercive means: 'She reiterated the fact that she was kept locked in the house and he had assaulted her'. This shows that the perpetrator wanted to maintain superiority over Diana, which involved physical abuse. In doing so, the perpetrator believed he was maintaining 'honour' due to visible domination over Diana. In Maddocks (2017), it was mentioned that the perpetrator often physically abused Anna to maintain 'honour' and dominance: 'in May 2008 occurred when the victim was six months pregnant with her second child; she was grabbed by the hair and was dragged and shaken at their home'. The context of this quote was that Anna wanted to report the perpetrator. It is observed that the perpetrator would have found this 'dishonourable', as it would have tainted his status due to his loss of control. Therefore, to maintain 'honour', he applied physical abuse towards Anna. In the DHR by Ross (2014), it was evidenced that Diana's family was aware of her abuse; 'She was clearly trying to identify her concerns about the relationship to her family, but it appears that assistance from her family to encourage her to make positive steps was not forthcoming'. This shows that Diana's family was aware of her abuse but did not chastise the perpetrator due to the 'shame' it would bring. This shows the unique experiences of domestic abuse within the South Asian community due to the concept of 'honour' - it entraps survivors to remain in abusive relationships, which are enforced by the perpetrator and close family connections.

\section{Financial coercion}

Referring to Maddocks (2017), the perpetrator often stole money that belonged to Anna. The perpetrator used the money to buy land in Bangladesh for status and power. The perpetrator often removed Anna's name from property deeds to maintain dominance: 'Adult 4 also stated that she was aware that the perpetrator had taken $£ 3000$ or $£ 4000$ from the victim's account although did not know the date'. From this quote, it is observed that the perpetrator was 
threatened by Anna's financial independence. The perpetrator wanted Anna to be dependent towards him - he wanted to maintain dominance: 'Escalation to murder included the ongoing dispute over the title deeds for the land purchase'. Maddocks (2017) claims that money was a catalyst for abuse as mentioned in section 68: 'I am satisfied that you have resorted on previous occasions to using violence against your wife in the course of disputes, mainly about money'. This quote highlights that obtaining money was a key reason why the perpetrator continuously abused Anna. The perpetrator wanted to buy land in Bangladesh, and thus improve his societal status. The perpetrator sought this via financial coercion. As such, Anna was a means to an end for the perpetrator. This situation created the 'perfect' environment for abuse as she was powerless. As the perpetrator was threatened, this shows the importance of economic independence in tackling abuse.

A family's 'honour' is highly dependent on ensuring the traditional norms of men and women are upheld (Gill, 2012; Gill, 2013; Aplin, 2019). Women are expected to be obedient to the male members of their family whilst men are expected to express superiority (Gill, 2004; Ahmad et al, 2009). In the DHR by Maddocks (2017), it was explained that the perpetrator stole money from Anna, approximately £4,ooo, in order to buy property in Bangladesh. This involved physically and psychologically abusing Anna in order to grow his status, power, and wealth despite the harm caused, which is embodying special liberty (Hall, 2012). The perpetrator felt a sense of entitlement that Anna's money belonged to him. As noted by Winlow and Hall (2019) and Yardley (2020), male abusers embody insecure neo-liberal insecurities. To tackle the threat of female economic impendence, a physical threat is used to establish dominance (Ellis, 2017). This is supported by previous research; it was found that male perpetrators of domestic abuse within the South Asian community often display physical abuse to assert domination when threatened by female family members' independence. As mentioned in the findings, in the DHR by Ross (2014), the perpetrator often locked Diana inside the house. With the neo-liberal notion of 'winning' and 'securing what is theirs' (Ellis, 2017; Dobash and Dobash, 2015), abusers seek to gain control through possession and domination (Yardley, 2020). This ties in with the concept of 'honour' in relation to the possession and domination of female family members to ensure family 'honour' and status is maintained.

\section{Recommendations}

\section{Funding}

A key issue that was evidenced in previous literature and both DHRs is that survivors of domestic abuse within the South Asian community are unable to receive funding and accommodation due to their immigration status. This recommendation argues that when individuals are in need of support against their abuser, immigration status should not matter. Everyone is entitled to support against domestic abuse, thus, the 'No Recourse to Public Funds' should be removed to provide support to the South Asian demographic and the wider community.

2. GP and police accountability

It was evidenced in previous literature and thematic analysis that GPs and the police have consistently neglected the survivors of domestic abuse within the South Asian community due to cultural ignorance. A recommendation for the Domestic Abuse Bill is to implement mandatory training for GPs and police officers amongst all ranks, which will educate them on domestic abuse and the significant differences within all ethnic backgrounds. This will better equip GPs and police officers to stop abuse from amplifying. Moreover, training should be provided regarding how institutions should work together rather than independently. This will prevent individuals working in the police or GP from pushing the responsibility to other agencies. 
Vol. 8, No. 1, 50-68.

\section{Implementation of neighbourhood committees}

As evidenced in previous literature and thematic analysis, many incidents of domestic abuse within the South Asian community go unnoticed by law enforcement or the authorities due to the concept of honour, thus preventing survivors from reporting their abuse. Many individuals from the South Asian community are not aware they are suffering from domestic abuse; this includes male survivors. They often dismiss their suffering in an attempt to remain masculine. Therefore, a recommendation is to implement neighbourhood committees across Britain, especially in residential areas of South Asian communities. This will consist of neighbourhood citizens working alongside the police to report any occurrences of domestic abuse within the community. With funding, citizens will be trained to understand cultural differences within domestic abuse. This will allow the police to proactively engage with the community.

\section{Note}

${ }^{1}$ Mikahil Azad is a Criminology graduate and Visiting Lecturer at Birmingham City University. mikahil. azad@bcu.ac.uk

\section{References}

Aghtaie, N. and Gangoli, G. (2014) Key issues: Researching gender based violence. In: N. Aghtaie \& G. Gangoli, eds. Understanding Gender Based Violence: National and International Contexts. Oxon: Routledge, pp. 1-17.

Ahmad, F., Driver, N., McNally, M. and Stewart, D. (2009) 'Why doesn't she seek help for partner abuse?' An exploratory study with South Asian immigrant women. Social Study and Medicine, 69(4), pp. 613-622.

Anitha, S. (2010) No recourse, no support: State policy and practice towards South Asian women facing domestic violence in the UK. British Journal of Social Work, 4o(2), pp. 462-479.

Aplin, R. (2018) Honour based abuse: The response by professionals to vulnerable adult investigations. Journal of Aggression, Conflict and Peace Research, 10(4), pp. 239-250.

Aplin, R. (2019) Policing UK Honour-based Abuse Crime. London: Palgrave.

Begikhani, N., Gill, A. and Hague, G. (2016) Honour-Based Violence: Experiences and Counterstrategies in Iraqi Kurdistan and the UK Kurdish Diaspora. London: Routledge.

Belur, J. (2008) Is policing domestic violence intuitionally racist? A case study of South Asian women. An International Journal of Research and Policy, 18(4), pp. 426-444.

Bimbi, F. (2014) Symbolic violence: Reshaping post-patriarchal discourses on gender. Gendered Perspectives on Conflict and Violence, 18(1), pp. 275-301.

Black, N. (2019) Social Feminism. Cornell: Cornell University Press.

Bradshaw, J. (2013) The Women's Liberation Movement: Europe and North America. Oxford: Pergamon Press.

Brandon, J. and Hafez, S. (2008) Crimes of the Community: Honour-based Violence in the UK. London: Civitas.

Braun, V. and Clarke, V. (2006) Using thematic analysis in psychology. Qualitative Research in Psychology, 3(2), pp. 77-101. 
Brooks, A. (2002) Post Feminisms: Feminism, Cultural Theory, and Cultural Forms. 2nd edn. London: Routledge.

Brooks-Hay, O., McFeeley, C. and Burman, M. (2018) Domestic Abuse: Contemporary Perspectives and Innovation. Edinburgh: Dunedin Academic Press.

Broom, A., Sibbritt, D., Nayar, K., Nilan, P. and Doron, A. (2012) Men's experiences of family, domestic and honour-related violence in Gujarat and Uttar Pradesh, India. Asian Social Science, 8(6), pp. 3-10.

Bryman, A. (2016) Social Research Methods. 5th edn. Oxford: Oxford University Press.

Bumiller, K. (2008) In an Abusive State: How Neo-liberalism Appropriated the Movement Against Sexual Violence. United States of America: Duke University Press.

Burman, E. and Chantler, K. (2005) Domestic violence and minoritisation: Legal and policy barriers facing minoritized women leaving violent relationships. International Journal of Law and Psychiatry, 28(1), pp. 59-74.

Carr, M. and Campbell, H. (2018) Languages After Britain. London: Palgrave Macmillan.

Carrington, K. and Death, J. (2014) Feminist criminologists' contribution to understandings of sex, gender, and crime. In: R. Gartner \& B. McCarthy, eds. The Oxford handbook of Gender, Sex, and Crime. Oxford: Oxford University Press, pp. 99-117.

Chowbey, P. (2017) Women's narratives of economic abuse and financial strategies in Britain and South Asia. Psychology of Violence, 7 (3), pp. 459-468.

Dauvergne, C. and Millbank, J. (2010) Forced marriage as a harm in domestic and international law. The Modern Law Review, 73(1), pp. 57-88.

D'Cruze, S. and Jackson, L. (2009) Women, Crime and Justice in England since 1660. Hampshire: Palgrave Macmillan.

Dobash, E. and Dobash, R. (1992) Women Viewing Violence. London: Palgrave Macmillan.

Dobash, E. and Dobash, R. (2015) When Men Murder Women. Oxford: Oxford University Press.

Dyer, E. (2015) 'Honour Killings in the UK'. [pdf] London: The Henry Jackson Society. Available at: http://henryjacksonsociety.org/wp-content/uploads/2015/o1/Honour-Killingsin-the-UK.pdf [Accessed 1st November 2019].

ECHR. (2020) European Convention of Human Rights. [pdf] Strasburg: Council of Europe. Available at: https://www.echr.coe.int/Documents/Convention_ENG.pdf [Accessed 15th July 2020].

Ellis, A. (2017) Men, Masculinities and Violence: An Ethnographic Study. Oxon: Routledge.

Finley, L. (2016) Domestic abuse and sexual assault in popular culture. California: Praeger.

Frank, P. and Golden, G. (1992) Blaming by naming: Battered women and the epidemic of codependence. Social Work, 37(1). Available at: http://goldenwrites.com/BlamingNaming. pdf [Accessed 2oth November 2019].

Fraser, N. (2013) Fortunes of Feminism. London: Verso Books.

Fulu, E. (2014) Domestic Violence in Asia. Oxon: Routledge.

Gangoli, G. (2006) Engendering genocide: Gender, conflict and violence. Women's Studies International Forum, 29(5), pp. 534-538. 
Vol. 8, No. 1, 50-68.

Gangoli, G. and Razak, A. (2006) Forced marriage and domestic violence among South Asian communities in North East England. Northern Rock Foundation, 1(1), pp. 1-33.

Gill, A. (2004) Voicing the silent fear: South Asian women's experiences of domestic violence. The Howard Journal, 43(5), pp. 465-483.

Gill, A. (2006) Patriarchal violence in the name of 'Honour'. Journal of Criminal Justice Sciences, 1(1), pp. 1-12.

Gill, A. (2012) Intersecting inequalities: Implications for addressing violence against black and minority ethnic women in the United Kingdom. In: N. Lombard \& L. McMillan, eds. Violence Against Women: Current Theory and Practice in Domestic Abuse, Sexual Violence, and Exploitation. London: Jessica Kingsley Publishers, pp. 141-159.

Gill, A. (2013) Feminist reflections on researching so-called 'honour' killings. Feminist Legal Studies, 21(1), pp. 241-261.

Gill, A. (2014). Honour and honour-based violence: Challenging common assumptions. In: A. Gill, C. Strange \& K. Roberts, eds. From 'Honour' Killing and Violence: Theory, Policy, and Practice. London: Palgrave Macmillan Limited.

Gill, A. (2017) Women murdered in the name of 'honour'. In: F. Brookman, E. Maguire \& M. Maguire, eds. The Handbook of Homicide. Sussex: John Wiley \& Sons Ltd, pp. 149-165.

Gill, A. (2019) Social and cultural implication of 'honour'-based violence. International Human Rights of Women, 7(3), pp. 365-380.

Gill, A., Begikhani, N. and Hague, G. (2012) 'Honour'-based violence in Kurdish communities. Women's Studies International Forum, 35(2), pp. 75-85.

Gov. UK. (2020) Domestic Abuse Bill 2020: Overarching factsheet. [pdf] London: Home Office. Available at: https://www.gov.uk/government/publications/domestic-abuse-bill2020-factsheets/domestic-abuse-bill-2020-overarching-factsheet [Accessed 24th March 2020].

Grierson, J. (2020) Domestic abuse killings 'more than double' amid Covid-19 lockdown. The Guardian, 15 April. Available at: https://www.theguardian.com/society/2020/apr/15/domesticabuse-killings-more-than-double-amid-covid-19-lockdown [Accessed ist June 2020].

Guest, G., MacQueen, K.M. and Namey, E.E. (2012) Applied Thematic Analysis. London: Sage Publications.

Hall, S. (2012) Theorizing Crime and Deviance: A New Perspective. London: Sage Publications. Hall, S. and Winlow, S. (2015) Revitalizing Criminological Theory: Towards a New UltraRealism. Oxon: Routledge.

Hayes, D. (2019) Domestic abuse. Children and Young People Now Select, (5), pp. 1-9.

Hegarty, K. (2011) Domestic violence: The hidden epidemic associated with mental illness. The British Journal of Psychiatry, 198(3), pp. 169-182.

Heidensohn, F. (1968) The deviance of women: A critique and an enquiry. The British Journal of Sociology, 19(2), pp. 160-175.

Helie, A. and Hoodfar, H. (2012) Sexuality in Muslim Contexts: Restrictions and Resistance. London: Zed Books.

Hill, J. (2019) See What You Made Me Do: Power, Control and Domestic Abuse. Australia: Schwartz Publishing Ltd. 
Home Affairs Committee. (2018) Domestic Abuse: Ninth Report of Session 2017-19. [pdf] House of Commons: Order of the House. Available at: https://publications.parliament.uk/ $\mathrm{pa} / \mathrm{cm} 201719 / \mathrm{cmselect} / \mathrm{cmhaff} / 1015 / 1015 . p d f$ [Accessed 29th October 2018].

Home Office (2016) Domestic Homicide Reviews: Key Findings from analysis of domestic homicide reviews. [pdf] London: Home Office. Available at: https://assets.publishing.service. gov.uk/government/uploads/system/uploads/attachment_data/file/575232/HO-DomesticHomicide-Review-Analysis-161206.pdf [Accessed 1st November 2019].

Johnson, M. (2010) A Typology of Domestic Violence: Intimate Terrorism, Violence Resistance and Situational Couple Violence. Lebanon: North-eastern University Press.

Khan, R., Saleem, S., Lowe, M. (2018) "Honour"-based violence in a British South Asian Community. Safer Communities,17(1), pp. 11-21.

Largan, C. and Morris, T. (2019) Qualitative Secondary Research. London: Sage Publications Limited.

Leitner, H., Peck, J. and Shephard, E. (2007) Contesting Neoliberalism. New York: The Guildford Press.

Living Without Abuse (2020) Understanding Abuse: Statistics. Available at: https://www. lwa.org.uk/understanding-abuse/statistics.htm [Accessed 3rd March 2020].

Lombroso, C. and Ferrero, G. (1895) The Female Offender. Boston: Appleton \& Company.

Lynes, A., Ntanos, L., Yardley, E. and Winch, R. (2020) Making Sense of Homicide: A Student Textbook. Reading: Waterside Press.

Maddocks, P. (2017) Domestic homicide review: Under section nine of the Domestic Violence Crime and Victims Act 2004. In respect of the death of a woman. [pdf] Birmingham: Birmingham Community Safety Partnership. Available at: https://www.birmingham.gov.uk/info/50222/ community_safety/1948/domestic_homicide_reviews [Accessed 2oth Oct 2019].

Matthew, B. and Ross, L. (2010) Research Methods: A Practical Guide for the Social Sciences. Essex: Pearson Education Limited.

Mirza, N. (2016) The UK government's conflicting agendas and 'harmful' immigration policies: Shaping South Asian women's experiences of abuse and exit. Critical social policy, 36(4), pp. 592-609.

Monckton-Smith, J., Williams, A. and Mullane, F. (2014). Domestic Abuse, Homicide and Gender: Strategies for Policy and Practice. Basingstoke: Palgrave Macmillan.

Naffine, N. (1997) Feminism and Criminology. Cambridge: Blackwell Publishing Limited.

Niaz, U. (2003) Violence against women in the South Asian countries. Archives on Women's Mental Health, 6(1), pp. 173-184.

Nicholson, L. (2013) Feminism/Postmodernism. London: Routledge.

Office of National Statistics. (2020) Domestic abuse in England and Wales overview: November 2019. [pdf] London: Home Office. Available at: https://www.ons.gov.uk/peoplepopulationandcommunity/crimeandjustice/bulletins/domesticabuseinenglandandwalesoverview/ november2019 [Accessed 23rd March 2020].

Oppenheim, M. (2020) Gender-based violence surging among 'displaced women during pandemic'. The Independent, 10 June. Available at: https://www.independent.co.uk/topic/ domestic-abuse [Accessed ist July 2020]. 
Vol. 8, No. 1, 50-68.

Payton, J. (2014) 'Honour,' collectively, and agnation: Emerging risk factors in 'honour'based violence. Journal of Interpersonal Violence, 29(16), pp. 2863-2883.

Philips, A. and Dustin, M. (2004) UK initiatives on forced marriage: Regulation, dialogue and exit. Political Studies, 52(3), pp. 531-551.

Pringle, K. (1995) Men, Masculinities and Social Welfare. London: University College London Press.

Rafter, N. and Gibson, M. (2004) The Criminal Man. Available at: http://www.twill.info/wpcontent/uploads/2013/03/criminal_man.pdf [Accessed 1st March 2020].

Rahman, M. (2019) Homicide and Organised Crime: Ethnographic Narratives of Serious Violence in the Criminal Underworld. Switzerland: Palgrave Macmillan.

Raj, A. and Silverman, J.G. (2002) Intimate partner violence against South Asian women in greater Boston. American Medical Women's Association, 57(2), pp. 112-114.

Reddy, R. (2008) Gender, culture and the law: Approaches to 'honour crimes' in the UK. Feminist Legal Studies, 16(1), pp. 305-321.

Roberts, K., Campbell, G. and Lloyd, G. (2013) Honour-Based Violence:Policing and Prevention. Boca Raton: Taylor \& Francis Group.

Ross, M. (2014) Domestic homicide review: Overview report. [pdf] Sandwell: Sandwell Partnership. Available at: http://www.sandwell.gov.uk/info/200324/domestic_abuse/2831/ domestic_homicide_reviews [Accessed 2oth October 2019].

Rottenberg, C. (2013) The Rise of Neoliberal Feminism. Oxford: Oxford University Press.

Rowlands, J. (2019) Reviewing Domestic Homicide - International practice and perspectives. [pdf] London: Winston Churchill Memorial Trust. Available at: https://www.wcmt.org.uk/ sites/default/files/report-documents/Rowlands\%20]\%202019\%2oFinal.pdf [Accessed 29th July 2020].

Serious Crime Act 2015, C.9. London: The Statutory Office.

Shahid, M. and Hyder, A. (2008) Deliberate self-harm and suicide: A review from Pakistan. International Journal of Inquiry Control and Safety Promotion, 15(4), pp. 233-241.

Sharma, K. and Gill, A. (2010) Protection for all? The failures of the domestic violence rule for (im)migrant women. In: R. Thiara \& A. Gill, eds. Violence Against Women in South Asian Communities: Issues for Policy and Practice. London: Jessica Kingsley Publishers, pp. 211-237.

Silvestri, M. and Crowther-Dowey, C. (2016) Gender and Crime: A Human Rights Approach. 2nd edn. London: Sage Publications.

Stark, E. (2009) Coercive Control: The Entrapment of Women in Personal Life. Oxford: Oxford University Press.

Thiara, R. and Gill, A. (2009) Violence Against Women in the South Asian Communities: Issues for Policy and Practice. London: Jessica Kingsley Publishers.

Treadwell, J., Lynes, A. and Kelly, C. (2020) Benign neglect, special liberty, and COVID19. Emerald Publishing. [blog] 17 June. Available at: https://www.emeraldgrouppublishing. com/topics/coronavirus/blog/benign-neglect-special-liberty-and-covid-19 [Accessed 2oth June 2020].

Tudor, K. (2018) Toxic sovereignty: Understanding fraud as the expression of special liberty within late-capitalism. Journal of Extreme Anthropology, 2(2), pp. 7-21. 
Whitehead, S., Talahite, A. and Moodley, R. (2013) Gender and Identity. Canada: Oxford University Press.

Wilson, A. (2009) Charting South Asian women's struggles against gender-based violence. In: R. Thiara \& A. Gill, eds. Violence Against Women in South Asian Communities: Issues for Policy and Practice. London: Jessica Kingsley Publishers.

Winlow, S. and Hall, S. (2013) Rethinking Social Exclusion. London: Sage Publications.

Winlow, S. and Hall, S. (2019) Shock and awe: On progressive minimalism and retreatism, and the new ultra-realism. Critical Criminology, 27(1), pp. 21-36.

Wykes, M. and Welsh, K. (2008) Violence, Gender and Justice. London: Sage Publications.

Yardley, E. (2020) Technology-facilitated domestic abuse in political economy: A new theoretical framework. Violence Against Women, pp. 1-20.

Yuval-Davis, N. (1998) Gender and Nation. In: R. Wilford, R. Miller \& R. Miller, eds. Women, Ethnicity and Nationalism: The Politics of Transition. London: Routledge, pp. 25-53. 